\title{
DA MEMÓRIA NASCE A HISTÓRIA: CLIO E A NARRATIVA DO NASCIMENTO DA ESCOLA DE POLÍCIA DOS GAÚCHOS
}

\section{MEMORY IS BORN THE STORY: CLIO AND THE NARRATIVE OF THE BIRTH OF THE POLICE ACADEMY OF THE GAUCHOS}

\begin{abstract}
RESUMO: Este artigo tem como objetivo descrever reconstruir a história da Escola de Polícia Civil do Rio Grande do Sul e como objetivo específico querer pesquisar sua história educacional. Nosso problema de pesquisa pretende resolver: Quando Academia ou Escola de Polícia Civil do Estado do Rio Grande do Sul foi fundada e quando se tornou de fato efetiva na participação da formação dos policiais civis do Estado do Rio Grande do Sul? A pergunta é pertinente, pois ainda existem dúvidas sobre estas questões. A metodologia utilizada foi a análise do discurso de Michel Foucault. Para a captação de dados foi utilizado a técnica da leitura e análise qualitativa de livros documentos, noticiários sobre a polícia civil gaúcha, estudo e leitura de textos, revistas e papéis que tivessem informações, comentários ou críticas quaisquer de dados oficiais relativos à história fundação da Escola de Polícia.
\end{abstract}

Palavras chaves: Escola de polícia. Academia de polícia. História da polícia. Polícia civil. Delegado de polícia.

ABSTRACT: This article aims to describe reconstruct the history of the School of Civil Police of Rio Grande do Sul and how specific goal want to research their educational history. Our research aims to resolve the problem: When Academy or School of Civil Police of Rio Grande do Sul was founded and when it became effective participation in fact the training of police officers in the state of Rio Grande do Sul? The question is relevant because there are still questions about these issues. The methodology used was discourse analysis of Michel Foucault. To capture data was used reading technical and qualitative analysis of books technique was used reading technical and qualitative analysis of books, documents, news about the civil police gaúcha, study and reading texts, journals and papers that will had information, comments or criticisms any official data relating to the history foundation of the Police Academy.

Keywords: School police. Police academy. History of police. Civil police. Police chief.

1 Doutorando em Ciência da Educação (12/2014). Mestre em Ciência da Educação (2007). Mestre em Filosofia (2010). Especialista em Ciência da Educação (2004). Especialista em Filosofia (2005). Todos pela Universidade Federal de Pelotas - UFPel. Especialista em Metodologia de Ensino (PUCRS). Universidade Federal de Pelotas - FepráxiS 


\section{Introdução}

No princípio era o Caos, assim dizia Hesíodo: "Sim bem primeiro nasceu Caos, depois também Terra de amplo seio (...)" (HESÍODO, 2007, p. 109). Bem semelhante foi a história da Escola de polícia Gaúcha: no princípio era o Caos, depois dela se originou a Academia de Polícia que deu bons frutos, de fato uma bela história. Este artigo tem como objetivo geral reconstituir a história da Escola de Polícia Civil ${ }^{2}$ do Rio Grande do Sul e como objetivo específico quer pesquisar sua história educacional. Com a elaboração deste artigo queremos dar o passo inicial para outros estudos sobre a história e a Escola de Polícia Civil do Estado do Rio Grande do Sul.

A problematização dos motivos da fundação da Escola de Polícia Civil Gaúcha é de interesse de toda instituição policial civil do Estado do Rio Grande do Sul, bem como para a comunidade local, intelectuais, cientistas criminais ou sociais, e na medida em que proliferar como estudo poderá fornecer elementos para um melhor entendimento entre as instituições Policiais e a comunidade para a qual se dirige. Nosso problema de pesquisa que pretendemos resolver é: "Quando Academia de Polícia Civil do Estado do Rio Grande do Sul foi fundada e como se tornou de fato efetiva na participação da formação dos policiais civis do Estado do Rio Grande do Sul?".

A metodologia que utilizamos neste artigo foi a análise do discurso de Michel Foucault e de sua técnica retirou-se a captação de dados e análises qualitativas de livros, noticiários, documentos, leitura de textos, revistas e papéis com informações, comentários ou críticas quaisquer de dados relativos à história fundação da Escola de Polícia. Feito estes esclarecimentos iniciais se pode a seguir entrar no conteúdo de mérito do trabalho.

2 A partir de agora toda menção designando a nomenclatura "Escola de Polícia ou Academia de Polícia" será sempre tendo em vista a "Escola ou Academia de Polícia Civil", nunca a "Escola de Polícia Militar", pois esta última não é objeto deste trabalho. 


\section{Clio e a Polícia Gaúcha ${ }^{3}$}

Entrar no espelho de Clio é "(...) entrar num mundo diferente que nos leva a uma aventura emocionante no mundo do conhecimento" (ROJAS, 2000, p. 303). É preciso reconhecer que existem motivos para que poucos historiadores se interessem pela história da Escola de Polícia do Estado do Rio grande do Sul: é que a Polícia Civil é uma instituição com algumas características semifechada que permite pouco acesso às pessoas estranhas e, menos ainda, aos historiadores.

Em Vigiar e Punir, Foucault (1987, p. 176) dizia que a polícia é "(...) um aparelho que deve ser coextensivo ao corpo social, e não só pelos limites extremos que atinge, mas também pelas minúcias dos detalhes de que se encarrega". Por isso é possível entender porque é pouca a literatura nesta área tão importante de nossa sociedade. Mas, a Escola de Polícia como instituição policial civil não é independente da sociedade que the funda. Todas as vezes que a instituição "Polícia Civil" entendeu que não necessitava da sociedade, a Escola de Polícia foi desativada. A Escola ou Academia de Polícia não é um órgão que tem vida própria independente da sociedade, porque se assim fosse, hoje já estaria sem suas principais funções que é a formação do profissional voltado para a defesa da sociedade rio-grandense.

Epitácio Torres (1978, p. 37) foi um escritor, e policial, que se importava muito com o estudo da história da Polícia Civil, mas não especificamente sobre a Polícia Civil Gaúcha. Em sua obra Polícia publicada em agosto de 1978, queixa-se desta falta de escritos sobre a Polícia Civil, dizendo que "(...) escassa é a bibliografia sobre a polícia sul-rio-grandense". Segundo Torres (1978, p. 37), a promulgação da constituição de 1824 outorgou às assembleias provinciais autorizações para legislar sobre matéria de Polícia Administrativa e Polícia Municipal, mas não autorizou sobre Polícia Judiciária. As antigas instituições legais que legislavam sobre a Polícia Civil já haviam iniciado historicamente com fundamentos distintos em relação à divisão entre as funções de Polícia

\footnotetext{
3 Todos os decretos e leis aqui citados fazem parte de meu acervo pessoal sobre a história da
} policial e da Academia de Polícia do Estado do Rio Grande do Sul. 
Administrativa e Polícia Judiciária.

Um estudo feito na Escola de Polícia Civil Gaúcha (ACADEPOL/RS), preparado pela museóloga Rosana Gauer $\operatorname{Kirchner}^{4}(2000-a$, p. 1) sobre a história da polícia do Rio Grande do Sul no Brasil demonstra que até a independência do Brasil e o advento da Constituição Política do Império do Brasil em outubro de 1822 vigorava as regras gerais das Ordenações Filipinas sobre a Província de São Pedro do Sul em matéria de polícia. Segundo este estudo em 1737 o governo fundou o Presídio do Rio Grande de São Pedro e construiu o forte Jesus-Maria-José. Nesta Época a capital da Província de São Pedro do Rio Grande do Sul era a cidade de Rio Grande. Era também o período da "Comandância Militar" efetuada para defender e organizar a ocupação do território Gaúcho, quando chegaram os primeiros colonos e casais açorianos. Com a chegada dos colonos portugueses alguns anos depois, em 1763, a capital da província se transfere para Viamão que se transforma na sede do governo.

Contudo, ocorre um fato que alterou a história do Brasil: a vinda da Família Real no ano de 1808, mas, apesar das anotações de Kirchner é Epitácio Torres que fornece maiores dados a respeito:

Ao chegar ao Brasil, encontrou D. João VI uma polícia composta por um corpo de quadrilheiros improvisados e rústicos, os quais não inspiravam nenhuma confiança ao monarca, motivos por que criou, através do Alvará de 10 de maio de 1808, a Intendência Geral de Polícia da Côrte e do Estado Geral do Brasil, inspirada no modelo português. Ocupou o cargo de Intendente Geral o Desembargador Paulo Fernandes Vieira. (TORRES, 1978, p. 31).

Até a Independência do Brasil, em 1822, vigoravam as leis da Metrópole Portuguesa, ou seja, as ordenações Filipinas e Manuelinas, inclusive em matéria de polícia. Mas, logo que estabelecida a independência, em 1822, a Constituição política do Império outorga em 1924 as assembleias legislativas provinciais o poder de legislar sobre Polícia.

4 Rosana Gauer Kirchner foi museóloga oficial da Academia de Polícia Gaúcha e a pedido da administração realizou um estudo sobre as diversas fases da instituição policial e do Rio Grande do Sul, datado de 17 de março de 2000, quando estava, na época, lotada no Museu Dr. José Faibes Lubianca na ACADEPOL/RS. Vide Referências Bibliográficas sobre seus estudos. 
Segundo Torres (1978, p. 38), as funções policiais foram descentralizadas através do código de processo criminal e exercidas por juízes de paz e juízes de direito. A Lei 261, em 1842, organiza as Polícias Civis das Províncias e prevê cargos de Chefe de Polícia, Delegados de Polícia e Subdelegados para posteriormente, pelo regulamento número 120, distinguir entre Polícia Administrativa e Polícia Judiciária. ${ }^{5}$ A lei 261 é mencionada por Torres que escreve:

(...) estruturam- se as polícias provinciais, através da lei no 261, de 3 de dezembro de 1841, com a criação da figura do Chefe de Polícia, delegado e subdelegado nomeados pelo Imperador e Presidentes de Província. A lei fazia distinção entre Polícia Administrativa e Polícia Judiciária, e seu regulamento falava do expediente da polícia, das nomeações, demissões, dos julgamentos, das contravenções e das posturas municipais. Tratava, ainda, da fiscalização dos teatros, das inspeções aos presídios e de outras atribuições pertinentes à atividade policial (TORRES, 1978, p. 38).

No início do século XIX, no Brasil começa a circular a ideia sobre a república e, como é comum em todos os países que passam por um período conturbado de ânimos acirrados, ocorrem revoltas. Por volta de 1835 eclode a Revolução Farroupilha que persiste por dez anos no Estado do Rio Grande do Sul (PESAVENTO, 1985, 37).

Com isso se torna constante a mudança de chefias à testa da Polícia Civil tanto no governo imperial como no governo revolucionário. Os revolucionários proclamam a República Rio-grandense. A cidade de Piratini se torna a nova sede e capital do Governo Revolucionário. O Chefe Geral de Polícia nomeado pelo Governo republicano é Bernardo Pires. Dessa forma, de acordo com o contexto histórico, uma parte da polícia do Rio Grande do Sul toma a forma do governo revolucionário republicano e a outra toma a forma do governo Imperial. Depois da revolução, o regime Imperial saindo vencedor cria em 1857 a Secretaria de Polícia da Província. A lei Imperial de no 2033 altera profundamente o Código de

\footnotetext{
5 Polícia Judiciária é a polícia repressiva dos crimes praticados contra a pessoa, que tem por obrigação a formalização das provas no inquérito policial, remetendo a justiça dentro do prazo legal. A Polícia Repressiva só age depois de praticado o crime e não é ostensiva (não se mostra preventivamente).
} 
Processo Criminal em 1871, fazendo com que as polícias se organizem conforme esta lei. Dai em diante o corpo policial se transforma na Força Policial através da lei 874 de 26 de abril de 1873.

Escreve Torres (1978, p. 32), que o Decreto no 120, de 1842 consagrou a divisão clássica das funções policiais em Polícia Administrativa e Polícia Judiciária. Essa estrutura perduraria até 1871, quando foi modificada. O processo inquisitório originário do Direito Canônico por determinação do papa Inocêncio III floresce na França, Alemanha, Espanha e outros países cultos.

Somente em quatro de janeiro de 1896, ainda conforme Kirchner (2000-c, p. 2) e Torres (1978, p. 33), o Estado, através da lei no 11, consegue reestruturar a organização policial constituindo seu primeiro estatuto com 79 artigos sintetizando todas as exigências dos serviços policiais daquela época. É neste ano que a lei $n \circ 24$ estabelece o Código de Processo Penal do Estado gaúcho ${ }^{6}$. Neste estudo da museóloga Kirchner, a Lei no 24 de 1898 estabeleceu o novo Código de Processo Penal do Estado, e no mesmo ano o decreto no 139 reorganizou o quadro da secretaria de polícia. Em 1907, o decreto no 1166 criou o Gabinete de Identificação, Antropometria e Estatística e o Instituto Médico Legal.

Neste período a evolução policial é contínua, e em 1929 as Guardas Municipais $^{7}$ são extintas, sendo criada a Guarda Civil subordinada ao Chefe de Polícia. Em 18 de janeiro, através do decreto no 4.256 é criado a Polícia Administrativa, o "Corpo de Guarda Civis" no então governo do presidente Getúlio Dornelles Vargas.

Para Torres (1978, p. 33) a partir de 1930, os estados passam a ter administração autônoma, tornando-se então a polícia uma instituição estadual. Apesar de algumas anomalias e falhas, a polícia brasileira evoluiu consideravelmente. Já se pode afirmar que passou sua rude e longa infância, pois esquecidos acham-se os tempos de Manuel Nunes Vidigal, o terror, dos súditos de D. João VI, o homem controvertido do relho e do azorrague, o

6 Nesta época a legislação penal e processual era local e a cargo de cada Estado Brasileiro.

7 As guardas municipais tinham menos competência legal que as policiais estaduais ou federais. 
perseguidor de capadócios e o carrasco de negros fugidos: instrumento de opressão e tortura. Como Torres afirma mais adiante:

Assim, a polícia sofreu, nos últimos tempos, significativas modificações, todas elas visando a eliminar definitivamente a violência, a prepotência e o arbítrio que lhe emprestavam policiais mal compenetrados de sua função e sem noção nítida do que fosse polícia. Atualmente, ela é encarada não como um instrumento de repressão a serviço de paixões pessoais e interesses subalternos, mas como um órgão de defesa social, capaz e digno. (TORRES, 1978, p. 33).

Apesar de todo o desenvolvimento do aparato policial, assim mesmo, até esta época a esperada Escola de Polícia ainda não havia sido criada. A partir de 1937 começam a surgir os primeiros indícios para o surgimento da tão esperada Escola de Polícia e apesar de tudo, a Escola teve sua institucionalização legal no Rio Grande do sul em sete de dezembro de 1937, através do Decreto 6880, do Interventor Federal no Estado, Gen. Daltro Filho. Este decreto também reorganiza a Polícia de carreira do estado, criando formalmente a Escola de Polícia Gaúcha. É em 1937, que se tem notícia pela primeira vez da Escola de Polícia, mas que infelizmente terá duração efêmera, funcionando precariamente por apenas um ano, sendo desativada sem se ter notícia da formação de algum agente ou autoridade policial (DOCUMENTARIO Vol. 2, 1959, p. 5).

É possível que se a Escola funcionasse efetivamente nestes períodos, as instruções repassadas a cada turma dariam uma base muito sólida para os policiais que viriam se formar com maiores credibilidades e possibilidades e poderiam entender as questões políticas e sociais que haveriam de ocorrer:

Vários anos transcorreram, assim, sem que nada de concreto se fizesse no sentido de seleção e da instrução teórica dos servidores policiais, não obstante os diplomas legais, que se sucederam ao até antes referido, continuassem a dispor expressamente - como se existente, de fato, fora - sobre a Escola de Polícia (DOCUMENTARIO Vol. 2, 1959, p. 5).

Alguns desses problemas decorrentes da história da brutalização dos 
policiais, ainda ocorrem nos dias de hoje. Os policiais mais antigos tem a percepção de que a polícia é um apêndice do executivo e por isto muitas vezes se verificam decisões políticas, sem amparo na legislação ou decisão judicial, sendo exigidas por chefes de polícia ou secretários de segurança que não assumem o risco do acometimento de crime em obediência a uma determinação as vezes não manifestamente ilegal. Toda legislação, em conjunto, mostra que pelo menos a Polícia Civil, ou polícia judiciária repressiva e discreta, tem a função prioritária de auxiliar ao juiz na coleta das provas e dos indícios do crime e da sua autoria. O mesmo não pode ser dito sobre a polícia preventiva, porque de fato esta tem uma função ostensiva cujo objetivo não é a investigação do crime, mas a prevenção destes.

Esta previsão legal leva a entender que a polícia militar está mais ligada aos órgãos do executivo e que a Polícia Civil está mais ligada às instâncias do Poder Judiciário e membros do Ministério Público. Em tempos pós-modernos, não é mais justificável a expressão Polícia Militar, porque esta implica um estado de beligerância que só era justificável às épocas das situações de guerras ou revoluções. Como isso não acontece atualmente o mais correto seria atribuir a expressão Polícia Ostensiva com função preventiva, por isso fardada, e mais próxima da sociedade.

No governo Vargas, os serviços policiais são novamente reorganizados, criase o Departamento de Ordem Política e Social- DOPS, que passa a exercer o serviço secreto e político do Estado, além do controle sobre armas e munições. $\mathrm{Na}$ verdade, aqui temos um aparte: o DOPS embora tivesse estas funções mencionadas funcionou exatamente como um apêndice do executivo. $\mathrm{Na}$ verdade, um grande apêndice do governo exercendo funções que de longe extrapolavam a sua competência legal. É nesta criação que a figura da repressão política aparece na história da polícia. A política se encarna na polícia com a criação do DOPS e com ela realiza desmandos que até hoje os policiais mais extremados não ousam defender. Neste ano também foram criados, através do decreto no 7.601, a Central de Polícia e as Delegacias Especializadas.

Nos anos seguintes, em 1941, surge o Código de Processo Penal unificado 
pela Lei 3.689 para todo o país, fazendo com que as polícias novamente tenham de se readaptar a legislação processual penal. Em 1946 a Lei no 1199 funda o Conselho Disciplinar de Polícia. E já em 1947, a Lei 1446 cria o Conselho Superior de Polícia e o Instituto de Polícia Técnica: uma evolução para a época. Nessa mesma lei também se cria a Diretoria Estadual de Segurança Social e Economia Popular que terá influências na fundação da Escola de Polícia, e também a Diretoria Estadual de Trânsito. A Diretoria de Radiocomunicações Policiais surge em 1950, pela Lei no 1195 . O primeiro Estatuto dos Servidores da Polícia Civil do Estado aparece em 1952, pela Lei no 1752, o que significa um avanço nas questões tanto de crime e infrações administrativas como de garantia de direitos. A Lei 2027, em 1953, reorganiza e altera a estrutura da Polícia Civil, inaugurando o Departamento de Polícia Civil do Estado do Rio Grande do Sul e a Delegacia de Estrangeiros que ficaria subordinada ao DOPS.

Finalmente em 1957, o Decreto 7.657 aprova o tão esperado regulamento da Escola de Polícia que vem a ser inaugurada em 31 de agosto de 1957 (DOCUMENTÁRIO Vol. 2, 1959, p. 7). Começa a história da Escola de Polícia que se tornará, no futuro, a atual Academia de Polícia Civil e Clio poderá narrar seu nascimento.

\section{A Narrativa de Clio: a fundação da Escola de polícia.}

No dia 23 de junho de 1952, um documento interno importantíssimo elaborado pelo então Diretor Estadual de Segurança Social e Economia Popular, Henrique Henkin (1952), através da portaria no 662 de maio daquele ano quando tinha sido incumbido pelo Chefe de Polícia para estudar a organização imediata da Escola de Polícia, seu funcionamento e a possibilidade de ter início logo no segundo semestre, também daquele ano. Nesta comunicação interna ${ }^{8}$ a resposta

\footnotetext{
8 O documento que deu base a estas informações se trata de uma Comunicação interna, Carta Resposta, sem número, datada de 23 de junho de 1952, em Porto Alegre, pelo então Diretor Estadual de Segurança Social e Economia Popular, Dr. Henrique Henkin ao Excelentíssimo Dr. Chefe de Polícia Do Estado do Rio Grande do Sul. A referida consta da Bibliografia.
} 
do diretor ao chefe de polícia é pontual: este documento mostra que o decreto $\mathrm{n}^{\circ}$ 7.601 de 05 de dezembro de $1938^{9}$ já havia criado a Escola de Polícia. O diretor afirma que a Escola havia funcionado por um ano e depois entrando em recesso sem ter restabelecido suas atividades. O diretor em questão cita que o Estatuto da Polícia Civil, a Lei no 1.752 de 23 de fevereiro de 1952, determinava a criação e organização efetiva da Escola de Polícia num prazo máximo de cento e cento e oitenta (180) dias.

Henrique Henkin (1952), neste documento, faz um comentário interessante ao dizer que a determinação legal é ociosa, pois a Escola de Polícia nunca fora extinta, ela apenas havia parado de funcionar. Era preciso então fazê-la funcionar dando-Ihe a adequada organização dinâmica e após seu funcionamento seria necessário de imediato à vigência de um regulamento para a Escola de Polícia, o qual já estava sendo preparado. A escola teria seu funcionamento inicial a título precário no antigo prédio do Estado, situado à Rua Riachuelo esquina General Canabarro, mas sua instalação definitiva dependeria de um prédio em melhores condições de conservação.

No pensamento do diretor, Henrique Henkin (1952), para que se pudessem instalar os cursos era necessária a contratação professores especializados com uma bagagem de conhecimentos didáticos suficientes, mas estes profissionais não existiam no Rio Grande do Sul e seria necessário buscá-los em São Paulo onde estava naquela época a melhor Escola de Polícia do Brasil. Ao mesmo tempo era necessária a contratação de professores para outras cadeiras nos três cursos que eram previstos. Estes professores poderiam ser universitários, de curso secundário, ou com exercício nos estabelecimentos locais, podendo ser funcionários policiais, neste caso receberiam funções gratificadas.

Na documentação, uma "Carta Resposta" sem número do Diretor Estadual de Segurança Social e Economia Popular, Henrique Henkin, datada de 23 de junho de 1952 previa até mesmo o material, a relação de preços, quantidades, consumo, móveis e máquinas. Previa o quadro funcional estabelecendo um

9 Contudo, esta data é duvidosa, pois a maioria dos documentos mostra que a instituição formal e legal a Escola de Polícia teria sido em 07 de dezembro de 1937 e não em 05 de dezembro de 1938 como consta da carta. Veremos isso mais adiante. 
secretário, um assistente, dois datilógrafos, um arquivista, um servente, um zelador. O quadro de funcionários poderia ser revisto posteriormente, após o funcionamento normal da escola. A previsão da contratação de funcionários era de admissão como extranumerários para cargos isolados e daqueles que já eram funcionários na forma de função gratificada.

A Escola de Polícia, segundo Henrique Henkin, sendo insipiente e como não havia no Rio Grande do Sul professores qualificados para dar o conteúdo de ensinamentos de disciplinas sobre assuntos e programações policiais que ela necessitava precisava buscá-los na melhor Escola de Polícia do país a época: no caso a de São Paulo. Ele precisava viajar a São Paulo para buscar e conhecer o que fosse preciso sobre a Escola de Polícia e sobre qual literatura especializada ou coletâneas de aulas era ditado pelos mestres.

Para ele bastava um decreto do Poder Executivo abrindo crédito especial para fins de funcionamento da Escola de Polícia Gaúcha, visto que já havia a verba de reaparelhamento da Polícia. O então Diretor da Escola de Polícia Henrique Henkin havia realizado até um cálculo aproximado do crédito devidamente calculado. Para mostrar melhor seu empenho junta um esquema de currículo escolar que tinha por objetivo o início do funcionamento da escola: o currículo definitivo poderia ser constituído depois de promulgado o regulamento da Escola.

Ao final do documento, o Diretor Estadual de Segurança Social sugere o encaminhamento imediato ao Secretário do Interior e Justiça a fim de que fosse tramitada a lei para um crédito especial. Este documento estava datado de $1952^{10}$, contudo a Escola de Polícia só funcionaria precariamente por um ano no prédio do Estado do Rio Grande do Sul, situado à Rua Riachuelo esquina General Canabarro em Porto Alegre, sendo desativada posteriormente ao primeiro ano de existência, porque o prédio não tinha as condições de conservação, sem se ter notícias da formação de algum agente ou autoridade policial. Mais uma vez a fundação de fato foi prorrogada embora de direito a Escola de Polícia já existisse.

10 Carta Resposta, sem número, datada de 23 de junho de 1952, em Porto Alegre, pelo então Diretor Estadual de Segurança Social e Economia Popular, Henrique Henkin. 


\section{A fundação da Escola de Polícia narrada por Clio}

A história mostraria que, só depois de cinco anos da data deste documento a Escola de Polícia do Estado do Rio Grande do Sul seria definitivamente instalada. Isso, levando-se em conta os memoriais, retrospectivas históricas e documentos constantes na revista "DOCUMENTÁRIO", publicada a partir dos primeiros cinco anos da inauguração da referida Escola. Sua finalidade era divulgar as atividades da escola. A primeira revista editada é volumosa se apresentando rica em dados a respeito da instalação e acontecimentos relacionados à Escola de Polícia.

No volume inicial existem fotos de pessoas e das placas quando da inauguração da Escola de Polícia. E desde sua inauguração a escola demonstra uma relação cordial com o judiciário representado na figura do Desembargador Balthazar Gama Barboza que fora convidado para proferir a Aula Inaugural. O texto inicial que fala da inauguração da Escola leva o título "Placa Comemorativa". E nele foi transcrito:

Numa cerimônia simples e solene foi inaugurada no dia 31 de agosto de 1957 a ESCOLA DE POLÍCIA do Rio Grande do Sul. O desembargador Balthazar Gama Barboza, diretor da Faculdade de Direito da Pontifícia Universidade Católica do Rio Grande do Sul especialmente convidado pela direção da Escola de Polícia, proferiu a aula inaugural dos cursos, versando sobre o tema "O EXERCÍ́CIO DO PODER DE POLÍCIA E O DIREITO" (DOCUMENTÁRIO Vol. 1, 1957, p. 6).

$\mathrm{Na}$ aula inaugural Barboza fala sobre as aptidões do policial que se formariam na nova era da Escola de Polícia, uma polícia melhor preparada tanto no aspecto psicológico como jurídico ressaltando:

A fundação da Escola de Polícia é acontecimento marcante na história administrativa do Rio Grande, e seu objetivo está bem assinalado na lei: "A Escola de Polícia é destinada a aperfeiçoar os conhecimentos técnicos, bem como a elevação do nível intelectual e moral dos servidores, necessários ao bom desempenho das funções policiais" (art. 33 da lei no 2027 de 03.01.1953). Aos que 
detêm parcelas do poder, deve exigir-se muito, e a mentalidade de que devem estar imbuídos é a do respeito aos limites dêsse ${ }^{11}$ [sic] poder, não invadindo zonas que a lei interdita. Só homens de elevado nível moral e devidamente formados no respeito aos direitos daqueles que esperam dos representantes da autoridade pública propiciação [Sic] de segurança e de ambiente adequado ao desenvolvimento normal das atividades lícitas, podem desempenhar essa missão (DOCUMENTÁRIO Vol. 1, 1957, p. 27).

Em outra passagem Barboza discursa sobre o conceito de polícia de Bielsa, afirmando:

No conceito hoje dominante de polícia compreende-se a faculdade ou poder jurídico, por parte da administração pública de estabelecer limitações e exercer coativamente sua atividade com o fim de regular o uso da liberdade pessoal e promover o bem estar geral (DOCUMENTÁRIO Vol. 1, 1957, p. 25).

Em seguida ele menciona sobre princípios de direito destacando fundamentalmente não só o positivismo, mas também o poder discricionário da autoridade pública:

No direito constitucional, frente ao direito do cidadão, está o direito do Estado expressado em princípios firmes e constantes de direito positivo, enquanto no direito administrativo o preceito legal completa-se freqüentemente $^{12}$ (sic) com a necessidade de uma apreciação discricionária reservada a autoridade pública (DOCUMENTÁRIO Vol. 1, 1957, p. 25).

Fundamentalmente, menciona Barboza, o "(...) povo rio-grandense tem o direito de esperar muito da escola que hoje inicia as atividades, no sentido de criar a mentalidade policial que convém aos interesses populares, e ao Estado, formando o caráter dos policiais (...)" (DOCUMENTÁRIO Vol. 1, 1957, p. 27).

Aqui vemos expressos historicamente os objetivos da fundação da Escola de Polícia, qual seja a formação de homens que sejam capazes de respeitar os limites da lei e do poder propiciando o exercício e desenvolvimento de atividades

${ }^{11}$ (Sic) A palavra "dêsse" está grafada desta forma no documento original. A palavra "Propiciação" está grafada desta forma no documento original.

12 (Sic) Grafado no original. 
lícitas. Mais adiante o orador, citando o mesmo autor, destaca que:

(...) não se deverá concluir que a polícia é essencialmente ação material do Estado. Pelo contrário, embora se proponha atingir fatos e bens na ordem material, é principalmente sobre a vontade humana que a polícia atua - sobre as vontades que regem e movem, no espaço e no tempo os fatos do homem e as cousas postas ao seu serviço (DOCUMENTÁRIO Vol. 1, 1957, p. 27).

No final do discurso é contundente ao afirmar: "O poder sobre os outros homens, o tremendo poder de atuar sobre a vontade dos outros, só de um modo pode ser adequadamente usado: servindo" (DOCUMENTÁRIO Vol. 1, 1957, p. 27).

Nada mais claro do que isto para mostrar qual a função da Escola de Polícia. Que isto não se realize, muitas vezes, é possível, mas não se pode tirar o valor da intenção. No dia da inauguração da Escola de Polícia outros discursos também marcaram a data: 1) o discurso do Tenente Coronel, Raymundo Lins de Vasconcelos Chaves, Chefe de Polícia do Estado do Rio Grande do Sul; 2) o discurso do Diretor da Escola de Polícia; 3) o discurso de encerramento de Hélio Carlomagno, Secretário do Interior e Justiça. O chefe de Polícia Raymundo Lins de Vasconcelos Chaves destacou:

Hodiernamente, o funcionário policial não é um ente estático. Ao invés, se acha pletórico de dinamismo, cheio de energia e sempre disposto ao serviço do povo do qual é parte integrante. Por conseguinte, além de assegurar a manutenção da ordem pública e a seguridade da população, deve estar em consonância com a nova concepção da Polícia, que é mais ampla, humana e justiceira. Deve compenetrar- se intimamente das novas leis, já que as forcas da ordem e do trabalho têm em comum uma só meta: tender a um mesmo ideal, que não é outro senão o bem estar da nação e a felicidade dos habitantes (DOCUMENTÁRIO Vol. 1, 1957, p. 15).

O diretor da Escola, Otacílio Gonçalves da Silva em discurso, remete mensagem à Escola de Polícia, falando sobre a simbologia da placa de inauguração. No discurso, destacou as inscrições das pirâmides egípcias e a dimensão extraordinária do esforço humano. Fala da pedra de Roseta que 
continha inscrições sobre as diversas dinastias que se sucediam no poder no alto e no baixo Egito, da importância dos hieróglifos nessas inscrições, da importância subsidiária das placas memoriais de passado remoto. A placa da inauguração da Escola de Polícia também é simbólica dos esforços de todos para a formação de três turmas que foram selecionadas do equivalente a 6.587 candidatos. Hélio Carlomagno em seu discurso destacou:

A Escola de Polícia impunha-se, por todos os títulos, como garantia do próprio funcionário que exerce o poder policial e, acima de tudo em relação à segurança e penhor da própria coletividade. Esta é precisamente a motivação fundamental da instalação da Escola de Polícia, no Rio Grande do Sul (DOCUMENTÁRIO, Vol. 1, 1957, p. 34).

\section{Clio narra o vínculo da Academia de Polícia com a guarda-civil de porto alegre ${ }^{13}$}

Faz-se necessário mencionar sobre a importância da Guarda Civil e sua existência porque no contexto histórico, educacional e didático, até seus últimos membros foram formados pela antiga Escola de Polícia e assimilados pela própria Polícia Civil e pela Brigada Militar. Ainda hoje a Escola, atualmente Academia de Polícia forma os Guardas Municipais do interior do Estado e também fornece outros cursos de vigilantes privados.

A museóloga Rosana Gauer Kirchner (2000-b, p. 1) também trabalhou na elaboração de um pequeno Histórico da Guarda Civil de Porto Alegre. Neste documento ela relata a criação da Guarda Civil pelo decreto no 4.256 de 18 de janeiro de 1929. A Guarda Civil era um órgão policial com existência paralela, preventiva e ostensiva com a Brigada Militar, e embora ostensiva e preventiva, distinguia-se porque não era militar como esta última, e, embora fosse uma Guarda Civil, preventiva e ostensiva, distinguia-se da Polícia Civil porque esta era

13 O documento elaborado pela Museóloga Rosana Gauer Kirchner se trata de um pequeno estudo sobre a Guarda Civil de Porto Alegre, encaminhado pelo Memorando no 008/2000, requisitado pelo Diretor da Academia de Polícia - ACADEPOL, pelo diretor do DEN/ACADEPOL, Aníbal Germany, datado de 17 de março de 2000, Porto Alegre. 
discreta e repressiva. A antiga Guarda Civil quando extinta pelo decreto no 18.501, de 20 de maio de 1967, teve seus policiais encampados pela Brigada Militar, a polícia ostensiva gaúcha, e pela Polícia Civil do Estado, durante o governo de Valter Perachi de Barcellos.

Segundo Kirchner (2000-b, p. 1), a existência da Guarda Civil originou-se de um convênio entre o Estado do Rio Grande do Sul, que tinha como presidente o Dr. Getúlio D. Vargas e o Município de Porto Alegre, dotando-se a capital do Estado de uma nova polícia: a Guarda Civil. Para o funcionamento desta polícia, as punições e nomeações seriam realizadas pelo chefe de Polícia que também imporia as penas disciplinares com o comandante da Guarda Civil enquanto não fosse aprovado um regulamento especial para esta Guarda. Assinado o convênio, Vargas declarava que as responsabilidades dos serviços policiais ostensivos por parte do estado não deveriam ficar restritas à capital.

É provável que a Polícia Civil no Estado do Rio Grande do Sul, quando anterior à Escola de Polícia, tinha a imagem e semelhança de um instrumento político manipulado por caudilhos. Esta imagem deveria ser destruída para reconstituir-se outra imagem que tivesse por finalidade dar proteção à vida, à moral e à propriedade. O município deveria então ser dividido em distritos policiais, cada um com o seu delegado de polícia, forma semelhante a que ainda se estrutura nos dias atuais.

A corporação assumiria o serviço de vigilância em diversos pontos da cidade que estava a cargo da Brigada Militar, e esta faria o policiamento a cavalo nos pontos mais afastados do Estado. O serviço da Guarda Civil seria gradativamente ampliado. A Guarda Civil, segundo a museóloga, em matéria política teve lugar destacado na revolução de 1930, quando participou da "Tomada do Quartel General do Exército" em Porto Alegre. Ao longo de sua existência, ela participou da evolução político histórica do Estado e do Brasil. Contudo, em 1967 ela foi extinta e seus membros optaram entre Polícia Civil, como investigadores ou como oficiais da Brigada Militar.

Diversos outros documentos foram elaborado e mantido pela Escola de Polícia como uma retrospectiva histórica anual e que levam o título de Escola de 
Polícia Civil: um breve histórico da academia ${ }^{14}$. Estes textos fazem parte daqueles que no todo contam a história da Escola de Polícia, porém trazem poucas novidades em relação aos primeiros deles, tornando-se muito repetitivos e resumidos, porém ainda constituem-se de algum valor na medida em que aos poucos acrescem dados à história da Escola de Polícia. Num destes documentos, a novidade é a referência a um dos locais onde funcionou a penúltima Escola de Polícia. O local exato, segundo o texto, era o antigo Restaurante Universitário da UFRGS, na Avenida Azenha onde atualmente funciona o prédio do Instituto de Identificação. Em 1986 a Escola de Polícia foi transferida para a Avenida Comendador Tavares ${ }^{15}, 360$, Bairro Navegantes, local onde se encontra até a data do presente artigo, sendo transformada em Academia de Polícia.

Em 1989, o nome de Escola de Polícia, através da Constituição Estadual do Rio Grande do Sul, alterou-se o nome da escola para Academia de Polícia Civil ACADEPOL. Depois destes textos que se referem a uma retrospectiva histórica da Escola de Polícia, nada de substancial tem se alterado.

\section{Clio e os retrospectos históricos ${ }^{16}$ da escola de polícia civil}

Nos arquivos da Escola de Polícia constam diversos documentos denominados "Retrospectos Históricos da Escola de Polícia". Um deles, que por coincidência não se chamava retrospectiva histórica, mas sim "História da Escola de Polícia", elaborado por seu diretor João Cândido Pasquali da Rosa (1993), todavia idêntica àquela na forma de elaboração, revela detalhes interessantes sobre estas retrospectivas como documentário. Por exemplo, a ação dos interventores Federais, os generais Daltro Filho, através do decreto no

${ }^{14}$ Este documento se trata de um memorial retrospectivo anual que sintetiza resumidamente os fatos mais marcantes da Escola de Polícia, atual Academia de Polícia do Rio Grande do Sul.

15 Até a data deste artigo, ano corrente de 2014, este ainda é o local o local onde funciona a Academia de Polícia.

16 O Retrospecto Histórico da Academia de Polícia Civil é documento elaborado pela biblioteca da própria Academia de Polícia com o objetivo de atualizar os acontecimentos durante o ano letivo na tentativa de manter uma retrospectiva da própria academia. Todos os anos ele é refeito e por isso é repetitivo, existindo vários deles. 
6880, na data de 07/12/1937 e Oswaldo Cordeiro de Farias, pelo decreto no 7601, em 05/12/1938, teriam organizado a polícia de carreira com base no direito constitucional criando e instalando a Escola de Polícia que teria como destino o adestramento dos policiais nomeados interinamente em virtude de aprovação em concurso público.

O próprio documento informa que a Escola de Polícia funcionou precariamente e por pouco tempo em razão do desinteresse de alguns governantes com a Escola, vindo a ser extinta não de direito, mas de fato. $\mathrm{O}$ documento histórico demonstra que a frustrada iniciativa e o subsequente fechamento da Escola fizeram retornar métodos antigos de ação e admissão de policiais sem a devida preparação para a atividade com o público.

O documento mostra que em 10 de dezembro de 1956, foi elaborada a lei 3.013 proposta para regular o ingresso e a promoção das carreiras policiais. No ano seguinte, em 1957, o decreto no 7.657 de 19 de fevereiro aprovou, finalmente, o sonhado regulamento da Escola de Polícia proporcionando que no dia 31 de agosto deste mesmo ano fosse finalmente instalada a Escola de Polícia, no terceiro pavimento do Edifício Santa Luzia, desta vez funcionando em um prédio destinado à futura sede do Departamento de Polícia Civil do Estado, na Avenida João Pessoa, em Porto Alegre, em um prédio que se achava ainda em construção (ROSA, 1993; DOCUMENTÁRIO Vol. 4, 1961, p. 21).

Com isso nasce o embrião da atual Academia de Polícia Civil como é chamada em vez de Escola de Polícia. O documento ${ }^{17}$ lavrado na própria Escola de Polícia destaca em letras maiúsculas o seguinte parágrafo sobre a instalação da Escola qualificando-a como: "O acontecimento mais importante da história da Polícia Civil, desde a criação da polícia de carreira em 1937, aduzindo que a escola determinará o desaparecimento do policial intuitivo para dar lugar ao policial capacitado".

Seguindo essa linha histórica, o desembargador Balthazar Gama Barboza,

\footnotetext{
17 Este documento interno foi elaborado pela biblioteca da Academia de Polícia Civil com o título "História da Academia de Polícia Civil" sem data, quando era Diretor João Cândido Pasquali da Rosa que havia tomado posse em 23 de março de 1993. A "parte destacada" do discurso foi grafada com letras maiúsculas.
} 
então diretor da Faculdade de Direito da PUC/RS, proferiu a aula inaugural dos primeiros cursos com o discurso "O EXERCICIO DO PODER DE POLÍCIA E O DIREITO ${ }^{18 " .}$. Estiveram presentes na cerimônia: o governador do Estado, Dr. Ildo Meneghetti; o desembargador Celso Afonso Pereira, presidente do Tribunal de Justiça do Estado do Rio Grande do Sul; o Dr, Hélio Carlomagno, presidente do interior e da Justiça do Estado do Rio Grande do Sul; o Dr. Júlio Aguilar Machado, diretor do foro de Porto Alegre; o Dr. Henrique Fonseca de Araújo, procurador-geral do Estado do Rio Grande do Sul; o tenente-coronel Raymundo Lins de Vasconcelos Chaves, chefe de polícia do Estado do Rio Grande do Sul; o Dr. Adaury Pinto Felippi, presidente da câmara de vereadores de Porto Alegre; o coronel Ildefonso Pereira de Albuquerque, comandante-geral da Brigada Militar do Estado do Rio Grande do Sul; o deputado estadual Walter Peracchi Barcelos e o diretor da Escola de Polícia do Rio Grande do Sul, o Delegado de Polícia Octacílio Gonçalves da Silva Filho. As frases de destaque mais importante dos discursos proferidos foram as de Raymundo Chaves, Chefe de Polícia:

O dever primordial da polícia é o de cumprir ela mesma, a lei e exigir, destarte, que os outros a cumpram, prevenindo, se possível, reprimindo, se necessário, e encaminhando o infrator ao poder competente para puní-lo na expectativa não só do castigo, mas também da regeneração (DOCUMENTÁRIO Vol. 1, 1957, p. 15).

Em seguida o mesmo texto destaca outra frase, do discurso de Balthazar Gama Barboza, Desembargador e Diretor da Faculdade de Direito da PUC/RS

Aos agentes do estado, no exercício do poder de polícia, importa conhecer o direito em vigor, para que não sejam transpostos os limites por ele fixado. O policial não é um ilota brutal e sem alma, mas um cidadão sem o qual os outros não poderiam viver em sociedade (DOCUMENTÁRIO Vol. 1, 1957, p. 15).

O documento assinala quais foram os primeiros professores da Escola de Polícia: Carlos Armando Gadret, professor de História da Polícia e Administração policial; Renato Souza e Afonso Brum, professores de Estatística e Dinâmica dos

18É, assim, com letras maiúsculas que está grafada no documento oficial. 
Serviços Administrativos policiais; Roberto Pinto Ribeiro e José Maria Wagner, criminologia; Otacílio Gonçalves, professor de Técnica do Crime e da Investigação; Rubem Lubianca, Sócrates Lubianca e Heraldo Rabelo ${ }^{19}$, professores de Criminalística; Delmar Araújo Ribeiro, professor de Política e Social; Telmo Pereira, professor de Medicina Legal; Paulo Pinto de Carvalho e Paulo Medeiros, professores de Direito Penal; Floriano Maia D'Ávila, professor de Processo Penal; Paulo Barbosa Lessa, professor de Institutos de Direito Público e Privado; Aldo Sirângelo, professor de Legislação Usual na Função Pública; Ney Messias, professor de Propedêutica Geral; Hipólito Kunz e Airton Santos Vargas, professor de Português; Rodolfo Pierri, professor de Contabilidade; Pedro Américo Leal e Rubens Lima Souza, professores de Educação Física; Hermano Wolf ${ }^{20}$, professor de Armamento, tiro e balística.

Consta também neste documento texto histórico que a Constituição Estadual do Rio Grande do Sul, no parágrafo único do artigo 134, altera a nomenclatura de Escola de Polícia para Academia de Polícia. Em 1962, é quebrada uma prática até então mantida, a de ser regida a Escola de Polícia por um bacharel que aliasse a condição de Delegado de Polícia com experiência profissional, constituindo coisa inédita nos anais da Antiga Escola, atual Academia de Polícia (DOCUMENTÁRIO Vol. 5, 1962, p. 18).

\section{Da memória nasce a história: a conclusão de Clio}

A história, dizem os historiadores, é a deusa Clio: a guardiã da memória. Loraine Slomp GIRON (2000, p. 23), no artigo Da Memória Nasce a História escreve que nos povos pré-históricos e ágrafos a memória tem um papel de importância vital porque é depositária do passado e garantia de manutenção da cultura e lembrança. O pastor de memórias que detinha a memória das tribos

19 Heraldo Rabello foi um policial admirado na Polícia Civil gaúcha em razão de seus altos conhecimentos de criminalística.

20 Da mesma forma, o professor Hermano Wolf tinha a consideração dos policiais civis gaúcho por seus conhecimentos de armamento, tiro e balística. 
primitivas era o encarregado de repassar o conhecimento histórico-cultural de seu povo para seu sucessor e este realiza a união entre o fato e a sua representação mantendo vivo o passado de seu grupo. De forma poética e didática ela explica sobre a origem da memória e da deusa Clio:

[...] sob o ponto de vista histórico, o interior da palavra memória guarda uma deusa: Mnêmesis. Segundo Hesíodo, a deusa Memória (Mnêmesis) é a "rainha das colinas de Eleutera", ou seja, a Terra da liberdade completa. Memória nasce dos amores do Céu (Cronos) e da Terra (Gea), sendo, ao mesmo tempo, a deusa protetora da justiça e da vingança. É a memória que realiza a ligação entre o mundo real de Gea e o mundo da representação de Cronos. Da ligação entre Zeus e Mnêmesis, nasce Clio (a História). Filha da Memória e de Zeus, senhor do poder do Olimpo, Clio tem seu berço no cume do poder terrestre e na representação do passado. Da união nascem ainda as nove musas. Para os gregos, a mãe Memória é a geratriz das artes. Sem memória não haveria as artes, nem a História, a primeira delas (GIRON, 2000, p. 23).

Ao iniciar esta conclusão, sinto-me forçado a retornar no tempo histórico de Clio e transcrever uma parte do processo dramático do sofrimento e da execução de Robert-François Damiens, ocorrido na França, em 1757, mencionado pelo filósofo e historiador, Michel FOUCAULT. Assim ele descreve a investigaçãocondenação-julgamento de Damiens, como na época dos juízes policiais em nosso Estado conforme descrito no corpo do artigo:

Damiens fora condenado, a 2 de março de 1757, a pedir perdão publicamente da porta principal da igreja de Paris [aonde devia ser] levado e acompanhado numa carroça, nu de camisola, carregando uma tocha de cera acesa de duas libras; [em seguida], na dita carroça, na praça de Grève, e sobre um patíbulo que aí será erguido, atenazado nos mamilos, braços, coxas e barrigas das pernas, sua mão direita segurando a faca que cometeu o dito parricídio, queimada com fogo de enxofre, e às partes em que será atenazado se aplicarão chumbo derretido, óleo fervente, piche em fogo, cera e enxofre derretidos conjuntamente, e a seguir seu corpo será puxado e desmembrado por quatro cavalos e seus membros e corpo consumido ao fogo, reduzido a cinzas, e suas cinzas lançadas ao vento (FOUCAULT, 1987, p. 9).

O processo de execução desta pena não foi apenas um processo de fato, foi 
também um processo psíquico porque o executado neste caso ainda teve forças para perdoar seus executores:

Os carrascos se reuniriam, e Damiens dizia-lhes que não blasfemassem, que cumprissem seu ofício, pois não lhes queriam mal por isso... Depois de duas ou três tentativas, o carrasco Sanson e o que the havia atezanado tiraram cada qual do bolso uma faca e lhe cortaram as coxas na junção com o corpo; os quatro cavalos, colocando toda forca, levantaram- Ihe as duas coxas de arrasto, isto é: a do lado direito por primeiro, e depois a outra; a seguir fizeram o mesmo com os braços, com as espáduas e axilas e as quatro partes; foi preciso cortar as carnes até quase aos ossos; os cavalos, puxando com força, arrebataram-lhe o braço direito primeiro e depois o outro (FOUCAULT, 1987, p. 10).

Mas, enfim, a sentença foi executada e aquele espetáculo deprimente se consumou: "Em cumprimento da sentença, tudo foi reduzido a cinzas. O último pedaço encontrado nas brasas só acabou de se consumir às dez e meia da noite" (FOUCAULT, 1987, p. 10).

É desse modo que Michel Foucault inicia Vigiar e Punir, narrando a execução de Robert-François Damiens, mas a narrando integralmente e não aos pedaços como faço aqui, de forma dolorosa, angustiante e nervosa: narra um fato histórico ocorrido em 1737, na França. Que demonstra como a justiça da época, onde promotoria, investigação, justiça e execução eram exercidas conjuntas, possibilitando flagrantes injustiças. É por isso a importância da Atual Academia de Polícia, formando policiais para agir em nome da lei, e não para condenar em nome da lei.

A história de Damiens é, com certeza, a história do pequeno. Esta história relatada reflete com perfeição a colocação de Jean Lacoutoure em sua exposição sobre a História Imediata, na obra com Jacques Le Goff, A História Nova no subtítulo: No imediato, os pequenos se calam:

Um "pequeno" quase sempre tem tudo a perder exprimindo-se. Ninguém lhe vai ser grato pela verdade que ele tiver proferido. Só saberá que ele falou quem achar que há reparos a fazer no que ele disse. Daí a dificuldade de enquête a rés-do-chão, pelo menos para aqueles que deve constituir rapidamente sua documentação 
(LACOUTOURE, 1988, p. 234).

A Escola de Polícia havia sido instituída legalmente pela primeira vez em 07 de dezembro de $1937^{21} \mathrm{sem}$ nunca funcionar. Isso só ocorreu de forma burocrática por apenas um ano em 1953 quando foi acionada, porém logo depois foi desativada. Ela só volta a funcionar em definitivo por uma grande pressão social com sua inauguração em 31 de agosto de $1957^{22}$, continuando até nossos dias. Verifica-se que somente depois de 20 anos de existência de direito é que passa a existir de fato.

É inegável que história da Escola de Polícia é uma relação direta com a educação e dominação do corpo porque adestra homens para aprenderem a lidar com seu próprio corpo e o corpo dos outros. A Escola de Polícia não pode escapar do controle social da sociedade, nem conseguirá fazê-lo, porque se o fizer fugirá dos seus propósitos. Os historiadores demonstram isto. Não só Foucault o esclarece, também André Burguière no Capítulo $A$ antropologia Histórica da referida obra A História Nova de Le Goff:

Suas pesquisas eram freadas por uma interrogação prévia: o corpo é objeto de História? Será possível identificar, entre a evolução da espécie e o ciclo biológico, formas de mudança mais complexas, devidas tanto ao meio histórico como ao meio cultural? (BURGUIÈRE, 1988, 137).

Burguière (1988, p. 132) explicita bem isso: "O próprio do poder é nunca estar exatamente onde se anuncia: é por isso que a história das instituições dá com frequência a impressão de acumular encontros não realizados".

${ }^{21}$ Aqui há um desencontro entre um Documento Interno, a Carta Resposta sem número de 23 de junho de 1952, remetido pelo então Diretor Estadual de Segurança Social e Economia Popular, Henrique Henkin dirigida Chefe de Polícia Civil, com a revista DOCUMENTÁRIO Vol. 5 e os anais de retrospectivas históricas da Academia e Polícia. A carta de Henkin anuncia o dia 05 de dezembro de 1938 como dia da instituição legal da antiga Escola de Polícia Civil e a Revista DOCUMENTÁRIO vol. 5 e todos os anais dos retrospectos históricos e demais documentos legais da Academia mostram o dia 07 de dezembro de 1937. Optou-se pelo dia 7 de dezembro de 1937 como dia da instituição legal da Academia de Polícia Civil em razão da maior credibilidade da revista DOCUMENTÁRIO e respectivos anais de retrospectos históricos.

22 A data da inauguração é unanimidade, como sendo 31 de agosto de 1957, em todos os cinco volumes da revista DOCUMENTÁRIO e demais documentos. 
Talvez não seja coincidência que foram infrutíferas a tentativa do funcionamento de uma Escola de Polícia, pois o estado de exceção exige uma polícia de exceção. Isso não quer dizer que a polícia fosse ruim, mas é o espelho de seu governo. Tudo que fosse visto como emperramento da máquina administrativa era suspeito e devia ser evitado.

O funcionamento de fato da Escola de Polícia ocorre no governo de Juscelino Kubitschek (JK) que avançou no modelo nacional desenvolvimentista e liberal positivista iniciado por Vargas. Desde 1930 foi sendo construído este modelo político e econômico com base na industrialização, mas somente teve seu apogeu na era JK, entre 1956 e 1961. Neste momento surge a condição propícia para que se desenvolva a Escola de Polícia.

Escola de Polícia visava na essência a formação do corpo: especificamente do corpo policial. Logo, o que estava em jogo era o poder. Sensivelmente pelo poder sobre o corpo, mas este sempre vem acompanhado pelo do poder político. O corpo sempre foi objeto de poder. O corpo do Senhor que possui o escravo. $O$ corpo do Estado sobre o corpo do homem: fosse ele criminoso ou policial. Mas sobre a história do corpo também o próprio Jacques Le Goff escreveu:

O desejo da História Nova de construir uma história do homem total, com seu corpo e sua fisiologia situados na duração social, a preocupação de alguns grandes biólogos com fazer da história de sua ciência um instrumento de pesquisa de uma maneira não externa, mas interna e ampliar suas pesquisas às dimensões da ecologia humana fazendo intervir a história, a geografia, a antropologia, a sociologia, a demografia, juntamente com a biologia propriamente dita, deixam entrever grandes perspectivas (LE GOFF, 1988, p. 48).

As decisões públicas diante do positivismo das leis se tornam úteis, como ficou patente no discurso do Desembargador Balthazar Gama Barboza, mas que na época e contexto da formação e fundação da Escola de Polícia, eram fatos inéditos e vistos como um grande avanço. Como ensina Barboza, o "povo riograndense tem direito de esperar muito da escola que hoje inicia as atividades, no sentido de criar a mentalidade policial que convém aos interesses 
populares, e ao Estado, formando o caráter dos policiais (...)" (DOCUMENTÁRIO Vol.1, 1957, p. 27).

Enfim, é este o resumo, a narrativa histórica de Clio da Academia de Polícia Civil do Estado do Rio Grande do Sul com suas nuances e vicissitudes como órgão policial que é. Contudo, embora a data da institucionalização da Escola de Polícia Civil como órgão policial possa ser duvidosa legalmente, a data da inauguração não é: Efetivamente em 31 de dezembro de 1957 a Escola de Polícia Civil do Estado do Rio Grande do Sul passou a ter vida ativa na formação dos policiais civis do Estado do Rio Grande do Sul.

\section{Referências}

BURGUIÈRE in Le GOFF, J.; CHARTIER, R.; REVEL, J. A História Nova. Trad. Eduardo Brandão. São Paulo: Martins Fontes, 1988.

FOUCAULT, M. Vigiar e Punir: nascimento da prisão. Trad. De Raquel Ramalhete. Petrópolis: Vozes, 1987.

FEBVRE, L. Combates Pela História. Porto, Portugal: Editora Presença, 1989.

GIRON, L. S. Da Memória Nasce a História. In: LENSKIJ, Tatiana; HELFER, Nadir Emma (orgs.). A memória e o Ensino de História. Santa Cruz do Sul: Edunisc; São Leopoldo: ANPUH/RS, 2000.

HESÍODO. Teogonia: a origem dos deuses. Tradução de Jaa Torrano. São Paulo: Iluminuras, 2007.

HILSDORF, M. L. S. História da Educação Brasileira: Leituras. São Paulo: Pioneira Thonsom, 2003.

LACOUTOURE in LE GOFF, J.; CHARTIER, R.; REVEL, J. A História Nova. Trad. Eduardo Brandão. São Paulo: Martins Fontes, 1988.

LE GOFF, J.; CHARTIER, R.; REVEL, J. A História Nova. Trad. Eduardo Brandão. São Paulo: Martins Fontes, 1988.

PESAVENTO, S. J. História do Rio Grande do Sul. Porto Alegre: Mercado Aberto, 1985.

RIO GRANDE DO SUL. Breve Histórico da Academia. Biblioteca da Academia de Polícia Civil do Rio Grande do Sul. Porto Alegre. sine nomine, [1990?].

RIO GRANDE DO SUL. Carta-Resposta ao Chefe de Polícia. Henrique Henkin Diretor Estadual de Segurança Social e Economia Popular. Sem número. 
23/06/1952.

RIO GRANDE DO SUL. DOCUMENTÁRIO. Volume 1. Inauguração da Escola de Polícia. Volume Especial I. Escola de Polícia. Porto Alegre: Imprensa Oficial, Agosto de 1957. 68 pág.

RIO GRANDE DO SUL. DOCUMENTÁRIO. Volume 2. Escola de Polícia. Porto Alegre: Imprensa Oficial: 1959, 45 pág.

RIO GRANDE DO SUL. DOCUMENTÁRIO. Volume 3. Escola de Polícia. Porto Alegre: Imprensa Oficial: 1960. 22 pág.

RIO GRANDE DO SUL. DOCUMENTÁRIO. Volume 4. Escola de Polícia. Porto Alegre: Imprensa Oficial: 1961. 23 pág.

RIO GRANDE DO SUL. DOCUMENTARIO. Volume 5. Escola de Polícia. Porto Alegre: Imprensa Oficial: 1962. 23 pág.

RIO GRANDE DO SUL. História da Academia de Polícia Civil. João Cândido Pasquali da Rosa - Diretor da Escola de Polícia. Biblioteca da Academia de Polícia Civil do Estado do Rio Grande do Sul. Sine Nomine, [1993]

RIO GRANDE DO SUL. Mensagem do Diretor da Escola de Polícia - Placa Alusiva a primeira aula. Otacílio Gonçalves da Silva Filho, Diretor da Escola de Polícia, 31/08/1957.

RIO GRANDE DO SUL. Retrospecto Histórico. Biblioteca da Academia de Polícia Civil do Rio Grande do Sul. Porto Alegre. Sine nomine: 31/08/1994.

RIO GRANDE DO SUL. Retrospecto Histórico. Biblioteca da Academia de Polícia Civil do Rio Grande do Sul. Porto Alegre. Sine nomine: [1997?].

RIO GRANDE DO SUL. Retrospecto Histórico. Biblioteca da Academia de Polícia Civil do Rio Grande do Sul. Porto Alegre. Sine nomine: [2001?].

RIO GRANDE DO SUL. Retrospecto Histórico. Biblioteca da Academia de Polícia Civil do Rio Grande do Sul. Porto Alegre. Sine nomine: 10/03/1999.

RIO GRANDE DO SUL. R. G. KIRCHNER. A Polícia no Brasil. Trabalho realizado no museu Dr. José Faibes Lubianca. In: Academia de Polícia. Porto Alegre: Anexos do memorando do Diretor da Divisão de Ensino da Academia de Polícia Civil para o Diretor da Academia de Polícia do Estado do Rio Grande do Sul, número 08/2000 de 17 de março de 2000-a.

RIO GRANDE DO SUL. R. G. KIRCHNER. Histórico da Guarda Civil de Porto Alegre. Trabalho realizado no museu Dr. José Faibes Lubianca. In: Academia de Polícia. Porto Alegre: Anexos do memorando do Diretor da Divisão de Ensino da Academia de Polícia Civil para o Diretor da Academia de Polícia do Estado do Rio Grande do Sul, número 08/2000-b de 17 de março de 2000.

RIO GRANDE DO SUL. R. G. KIRCHNER. Polícia no Rio Grande do Sul. Trabalho realizado no museu Dr. José Faibes Lubianca. In: Academia de Polícia. Porto Alegre: Anexos do memorando do Diretor da Divisão de Ensino da Academia de Polícia Civil para o Diretor da Academia de Polícia do Estado do Rio Grande do 
Sul, número 08/2000 de 17 de março de 2000-c.

ROJAS, C. A. A. Os Annales e a Historiografia Francesa: tradições críticas de March Bloch a Michel Foucault. Trad. Jurandir Malerba. Maringá, PR: Eduem, 2000.

RIO GRANDE DO SUL. Sobre a Academia. Biblioteca da Academia de Polícia do Estado do Rio Grande do Sul. Porto Alegre. Sine nomine, s/d.

TORRES, E. Polícia. Rio de Janeiro: Editora Rio - Sociedade Cultural Ltda, 1978.

Recebido em 06 de Julho de 2014.

Aprovado em 05 de Março de 2015. 